\title{
Obtaining and Characterization of Biodegradable Composites Reinforced with Microcrystalline Cellulose Fillers
}

\author{
Lucas Viana Costa, Gisele C. Valle Iulianelli, Paulo Sérgio Rangel C. da Silva, \\ Fernanda A. dos Santos
}

Instituto de Macromoléculas Professora Eloisa Mano, Universidade Federal do Rio de Janeiro, Rio de Janeiro, Brazil

Email: gisele@ima.ufrj.br

How to cite this paper: Costa, L.V., Iulianelli, G.C.V., da Silva, P.S.R.C. and dos Santos, F.A. (2021) Obtaining and Characterization of Biodegradable Composites Reinforced with Microcrystalline Cellulose Fillers. Materials Sciences and Applications, 12, 561-577.

https://doi.org/10.4236/msa.2021.1212037

Received: October 29, 2021

Accepted: December 4, 2021

Published: December 7, 2021

Copyright $\odot 2021$ by author(s) and Scientific Research Publishing Inc. This work is licensed under the Creative Commons Attribution International License (CC BY 4.0).

http://creativecommons.org/licenses/by/4.0/

\begin{abstract}
In recent years, there has been a growing discussion about the problems related to the massive use of many synthetic plastic materials, which inevitably leads to an increase in environmental pollution caused by the inappropriate disposal of these materials. In this sense, biodegradable materials have been a subject of great interest, as they are a real alternative to replace these materials and tackle this issue. In this work, fully biodegradable composites were prepared by solution casting method. Microcrystalline cellulose (MCC) and treated microcrystalline cellulose (TMCC) were separately incorporated into biodegradable PLA and PHB matrices at ratios of 3,5 and $7 \mathrm{wt} \%$ and the properties of the obtained biocomposites were evaluated by TGA, DSC, XRD and TD-NMR. From thermal analyses, it was seen that TMCC resulted in better thermal stability and $3 \mathrm{wt} \%$ of filler, in general, promoted a more pronounced thermal improvement. Furthermore Tg, Tc and Tm remained practically unchanged after MCC and TMCC addition. From XRD it was seen that the cellulose fillers influence in different ways the matrices, promoting increase or decrease in the degree of crystallinity. Finally, the results obtained by TD-NMR showed a decrease in the $\mathrm{T}_{1} \mathrm{H}$ values for all prepared biocomposites, indicating a good dispersion of the cellulose fillers in the matrices and pointed that the systems containing $3 \mathrm{wt} \%$ of cellulose fillers were the most homogeneous formulations.
\end{abstract}

\section{Keywords}

PHB, PLA, Microcrystalline Cellulose, Biocomposites, TGA, DSC, XRD, TD-NMR 


\section{Introduction}

In the last few decades, there has been a progressive increase in the production and use of petroleum-based polymers [1] [2]. The systematic growth of these synthetic materials production and their post-use disposal have resulted in a massive polymeric waste generation. This panorama can both contribute to fossil fuel depletion and environmental pollution. Consequently, the management of polymeric waste accumulation is becoming a major concern in terms of preserving the environment and sustainable development [3] [4].

In this regard, materials made of polymers from natural renewable sources or bio-based polymers, have been developed to replace traditional petroleum-based materials in many applications and, consequently, reduce the polymer waste problem and the global dependence on fossil sources [5]. Biodegradable polymers have important advantages over those obtained from petroleum such as biodegradability, biocompatibility, low toxicity, sustainability, among others [6] [7] [8] [9]. However, the wide application of these polymers is still a challenge due to inherent limitations on their performance in comparison to conventional polymers, which in general exhibit better mechanical properties and thermal stability [10].

Many studies have shown that the development of bio-based materials with natural reinforcement fillers, such as cellulose, starch, and chitin, appears as a promising strategy to provide the improvement of their properties [11]. Cellulose particularly has been largely employed to produce these fillers, granted being the most abundant biopolymer in nature and available from a wide variety of sources, such as plants and microorganisms [12] [13] [14] [15] [16]. In addition, the application of cellulose as the dispersed phase in biodegradable polymer matrices promotes in many cases enhanced performance concerning several factors, including barrier, thermal, and mechanical properties.

There are many reports about the reinforcing effects of cellulose-based filler or nanofiller incorporated into biodegradable polymer matrices [17]-[33], which demonstrate that the addition of low percentages of this type of fillers has positive effects on the structural properties of these polymers. However, obtaining optimal properties requires appropriate dispersion of cellulose particles within the polymer matrix. Ultrasonication treatment has been commonly used as a mechanical method to improve cellulose particles and nanoparticles dispersion in different solvents and polymer matrices [34]-[40].

In the present work, fourteen fully biodegradable films were developed by the solution casting method, in which seven were made with PLA, and the other seven with PHB. Microcrystalline cellulose was incorporated in these matrices at the ratios of 3, 5 and $7 \mathrm{wt} \%$. Besides comparing the influence of cellulose proportion, the present study also aimed at comparing the effect of the incorporation of microcrystalline cellulose without any treatment (MCC) and after being treated by ultrasonication (TMCC), since there are very few studies showing this comparison. The biocomposites obtained were characterized by conventional techniques, namely thermogravimetric analysis (TGA), differential scanning ca- 
lorimetry (DSC), X-ray diffraction (XRD) and by an unconventional technique, Time Domain-Nuclear Magnetic Resonance (TD-NMR). This technique, despite providing relevant information on the molecular dynamic behavior and homogeneity at the molecular level of hybrid materials such as composites and nanocomposites [41] [42] [43] [44], which contribute to the understanding of many properties of materials, has been little explored for the study of composite material. Moreover, scanning electron microscopy (SEM) was carried out to evaluate the effect of ultrasonication treatment on the morphology of microcrystalline cellulose filler.

\section{Materials and Methods}

\subsection{Materials}

The poly(3-hydroxybutyrate) (PHB) was supplied by PHB Indústria do Brasil, polylactic acid (PLA) was supplied by Nature works. Microcrystalline cellulose (MCC) ph102 powder was supplied by Viafarma. Treated microcrystalline cellulose (TMCC) was obtained by ultrasonication treatment of the MCC. Chloroform $\left(\mathrm{CHCl}_{3}\right)$ used as solvent was purchased from Merck.

\subsection{Preparation of the Microcrystalline Cellulose}

MCC was used as received, while TMCC underwent an ultrasonication treatment to verify a possible size reduction and shape modification and to investigate the influence of these parameters on the properties and homogeneity of the prepared systems. Ultrasonication treatment was carried out in an Eco-sonics equipment from Ultronique Company, Desruptor model, at a frequency of 20 $\mathrm{kHz}$ and potency of $500 \mathrm{~W}$. Aqueous suspensions containing MCC at $1 \mathrm{wt} \%$ were subjected to sonication at $25^{\circ} \mathrm{C}$ for $60 \mathrm{~min}$.

\subsection{Preparation of the Biocomposites Systems}

Biodegradable composites films were obtained by solution casting method, utilizing PHB and PLA as matrices and two types of cellulosic filler: MCC and treated MCC (TMCC). To obtain the cellulosic biocomposites systems, solutions of $\mathrm{PHB} / \mathrm{CHCl}_{3}$ and $\mathrm{PLA} / \mathrm{CHCl}_{3}$ at $10 \%$ w/v were separately prepared under magnetic stirring for 24 hours at room temperature. The PHB solution was subjected to an additional hour under magnetic stirring at $50^{\circ} \mathrm{C}$ to complete polymer solubilization. After the polymer solutions preparation step, $\mathrm{MCC} / \mathrm{CHCl}_{3}$ and $\mathrm{TMCC} / \mathrm{CHCl}_{3}$ dispersions at concentrations of 3, 5 and $7 \mathrm{wt} \%$ (filler/polymer) were prepared by magnetic stirring for $30 \mathrm{~min}$ at room temperature followed by sonication bath for $30 \mathrm{~min}$. Immediately after, the polymer solutions were added to the cellulosic fillers dispersions and the resulting mixtures were kept under constant magnetic stirring for 1 hour at room temperature. The materials obtained were poured into glass Petri dishes and placed in the exhaust hood at room temperature for at least seven days to eliminate all residual solvent. The materials obtained were coded as described in Table 1. 
Table 1. Codification and description of the obtained materials.

\begin{tabular}{cccc}
\hline $\begin{array}{c}\text { Code for } \\
\text { PHB systems }\end{array}$ & $\begin{array}{c}\text { Material } \\
\text { description }\end{array}$ & $\begin{array}{c}\text { Code for } \\
\text { PLA systems }\end{array}$ & $\begin{array}{c}\text { Material } \\
\text { description }\end{array}$ \\
\hline PHB & Unfilled PHB & PLA & Unfilled PLA \\
PHB/MCC 3 & PHB with 3 wt\% MCC & PLA/MCC 3 & PLA with 3 wt\% MCC \\
PHB/MCC 5 & PHB with 5 wt\% MCC & PLA/MCC 5 & PLA with 5 wt\% MCC \\
PHB/MCC 7 & PHB with 7 wt\% MCC & PLA/MCC 7 & PLA with 7 wt\% MCC \\
PHB/TMCC 3 & PHB with 3 wt\% TMCC & PLA/TMCC 3 & PLA with 3 wt\% TMCC \\
PHB/TMCC 5 & PHB with 5 wt\% TMCC & PLA/TMCC 5 & PLA with 5 wt\% TMCC \\
PHB/TMCC 7 & PHB with 7 wt\% TMCC & PLA/TMCC 7 PLA filled with 7 wt\% TMCC
\end{tabular}

\subsection{Characterization of the Microcrystalline Cellulose Fillers}

Scanning Electron Microscopy (SEM) technique was employed for direct investigation of the morphology of microcrystalline cellulose before and after ultrasonication treatment. The MCC and TMCC were analyzed in powder form, as samples were placed on a double-sided adhesive carbon tape after being sputter-coated with gold for 4 min. Images were taken with Hitachi TM3030 Plus scanning electron microscope (SEM) applying an accelerating voltage of $1-15$ $\mathrm{kV}$.

\subsection{Characterization of the Biocomposites}

Thermal stability of the materials was evaluated by thermogravimetric analysis (TGA) using a TA Instruments TGA Q500 with precision of $\pm 2^{\circ} \mathrm{C}$. The samples were placed in a platinum holder under continuous flow of nitrogen at a heating rate of $10^{\circ} \mathrm{C} / \mathrm{min}$ in the range from $20^{\circ} \mathrm{C}$ to $700^{\circ} \mathrm{C}$.

Differential scanning calorimetry (DSC) was carried out using a TA Instruments Q1000 calorimeter (with temperature accuracy of $\pm 2^{\circ} \mathrm{C}$ ) under a nitrogen flow rate of $50 \mathrm{~mL} / \mathrm{min}$. The temperature range for the test was from $-50^{\circ} \mathrm{C}$ to $200^{\circ} \mathrm{C}$, with heating and constant cooling at $10^{\circ} \mathrm{C} / \mathrm{min}$. The thermal data such as melting temperature $(\mathrm{Tm})$, crystallization temperature $(\mathrm{Tc})$ and glass transition temperature $(\mathrm{Tg})$ of systems were evaluated after subjection to a second heating ramp designed to remove the effect of prior thermal history.

Crystalline profile of the produced biocomposites was evaluated by X-ray diffraction (XRD) using a Rigaku Ultima IV diffractometer with $\mathrm{CuK} \alpha$ radiation generator $(\lambda=0.154 \mathrm{~nm}, 40 \mathrm{Kv}, 120 \mathrm{~mA})$ at room temperature, in the range of $2 \theta$ from $2^{\circ}$ to $40^{\circ}$ at a rate of $1^{\circ} / \mathrm{min}$ and step of $0.05^{\circ}$. The degree of crystallinity of the materials were determinated using Origin ${ }^{\circledR}$ software, according to the equation $\mathrm{XC}(\%)=\mathrm{IC} /(\mathrm{IC}+\mathrm{IA}) \times 100$, where $\mathrm{Xc}$ is the crystallinity degree; Ic is the sum of the areas under the crystalline peaks and IA is the area of the amorphous halo. The peaks were deconvoluted using Gaussian peak function.

Time Domain-Nuclear Magnetic Resonance (TD-NMR) was employed to determine the spin-lattice relaxation times of the hydrogen nucleus $(\mathrm{T} 1 \mathrm{H})$ and 
to plot the distribution domain curves, using a Maran Ultra spectrometer operating at $23 \mathrm{MHz}$, employing inversion-recovery pulse sequence (recycle delay$180^{\circ}-\tau-90^{\circ}-$ acquisition time). The analysis was carried out under the temperature of $27^{\circ} \mathrm{C}$; with $\tau$ values varying from 0.01 to $10,000 \mathrm{~ms}$ and recycle interval of $3 \mathrm{~s}$, using 40 points with 4 accumulations. The spin-lattice relaxation times were obtained with the aid of WinFit program and the distribution domain curves were fitted with WinDXP program.

\section{Results and Discussion}

\subsection{Characterization of the Microcrystalline Fillers}

Figure 1 presents the images obtained by scanning electron microscopy (SEM) for MCC and TMCC fillers. Images revealed that the ultrasonication treatment of MMC promoted changes both in size and shape of the particles. It was possible to observe that before treatment MCC fillers presented a more regular morphology exhibiting predominance of long structures (Figure 1(A) and Figure 1(B)). After ultrasonication treatment (Figure $1(\mathrm{C})$ and Figure $1(D)$ ) the microcrystalline
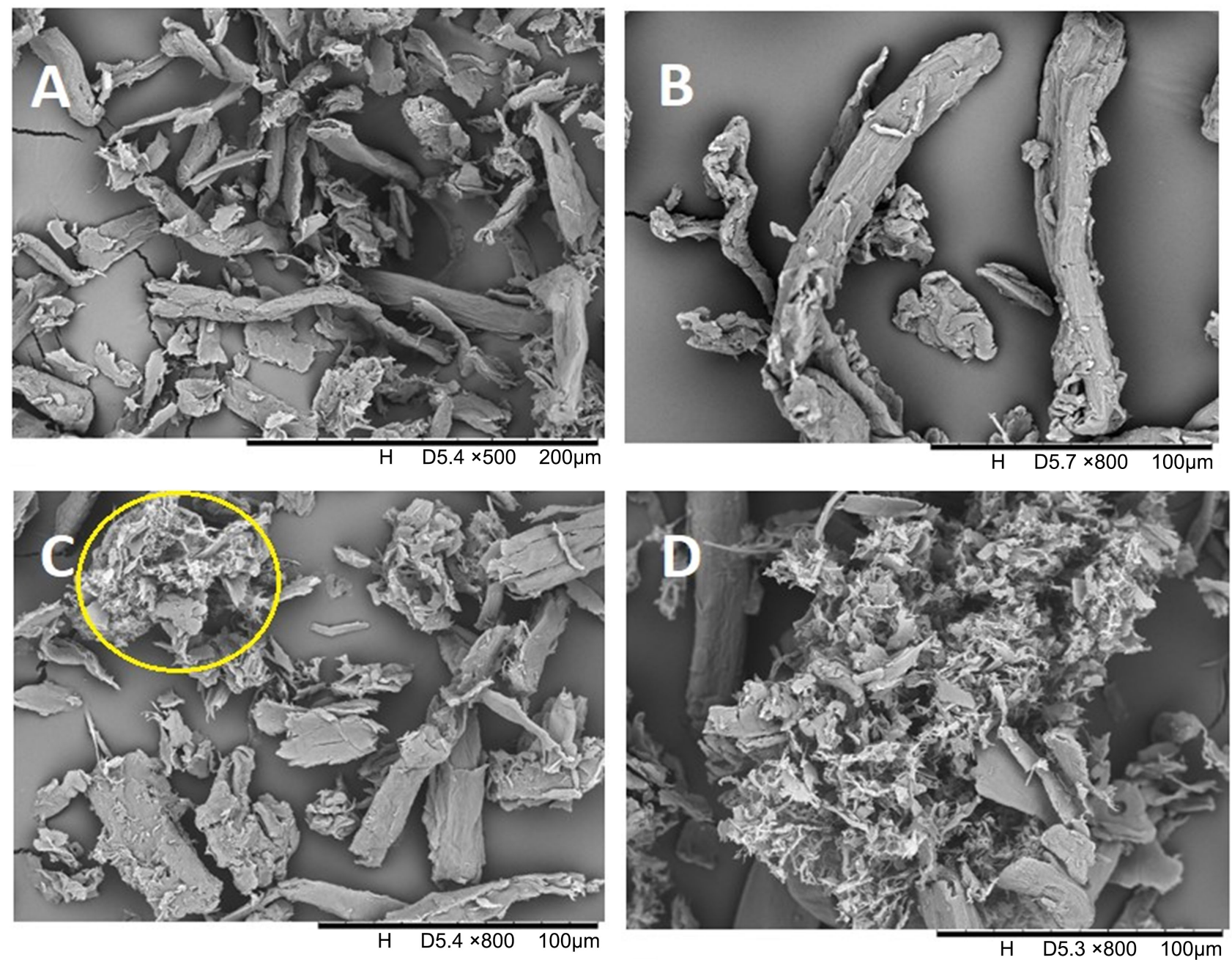

Figure 1. SEM images obtained for $\operatorname{MCC}(\mathrm{A}, \mathrm{B})$ and $\operatorname{TMCC}(\mathrm{C}, \mathrm{D})$. 
cellulose particles presented a reduction in size and a more irregular shape, with few long structures and the presence of aggregates of smaller particles (Figure 1(C) (yellow circle) and Figure 1(D).

\subsection{Characterization of the Biocomposites}

\subsubsection{Thermogravimetric Analysis (TGA)}

Two parameters were measured by thermogravimetric analysis to study the thermal stability of the prepared materials: the initial degradation temperature (Tonset) and temperature of maximum degradation rate (Tmax). The Tonset values were obtained from TG curves and denote the lowest temperature at which mass variation of the material occurs. In turn, the Tmax values were obtained from the peak of each DTG curve, which refers to the temperature where the degradation speed occurs more sharply. The results obtained from this analysis are denoted in Table 2 and Figure 2.

According to the results displayed in Table 2 and Figure 2 it was seen that for PHB biocomposites systems, the addition of MCC at $7 \mathrm{wt} \%$ and TMCC at 5 and 7 $\mathrm{wt} \%$ did not interfere significantly on the thermal stability of the PHB matrix, while
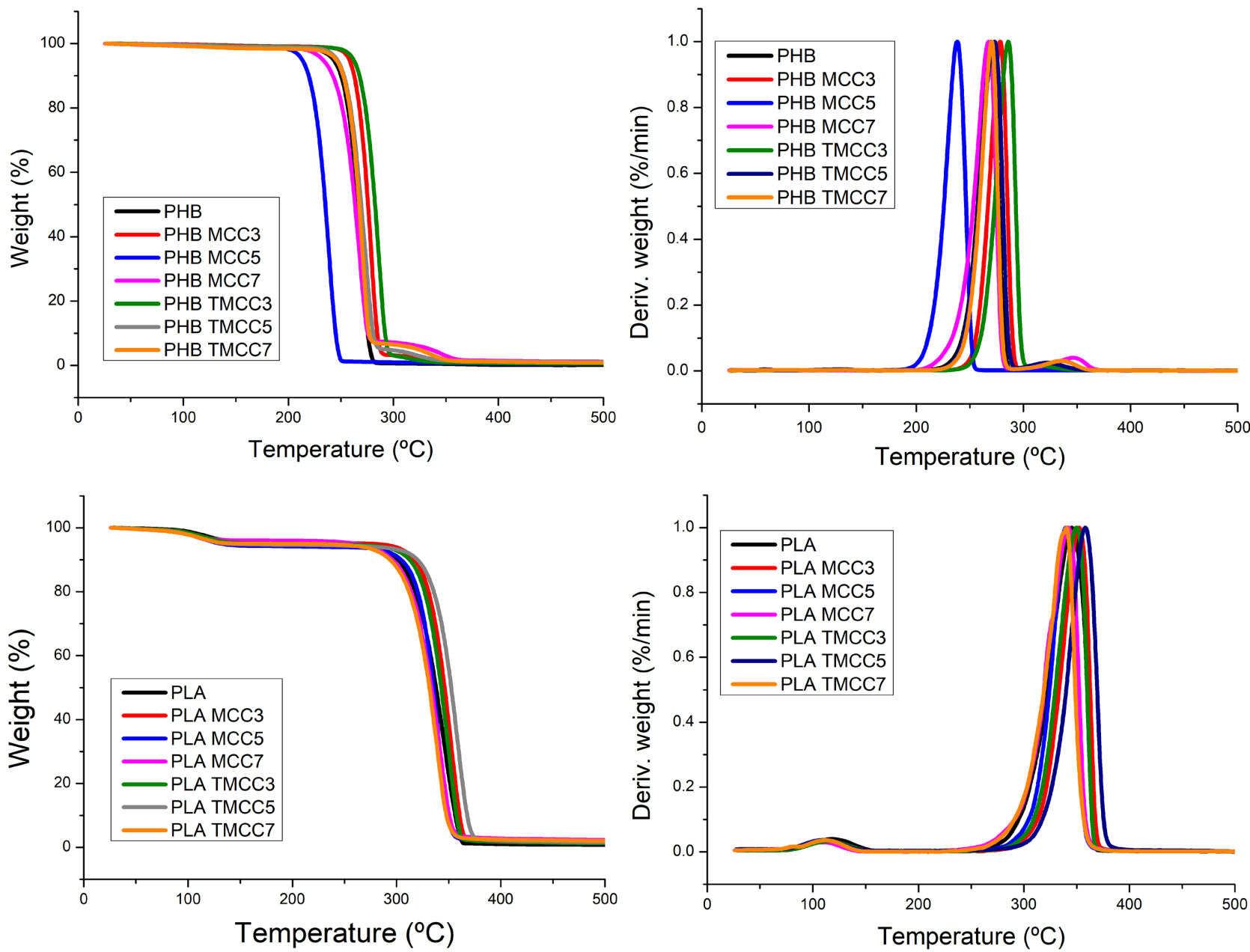

Figure 2. TG and DTG curves obtained for PHB, PLA and their biocomposites. 
Table 2. $\mathrm{T}_{\text {onset }}$ and $\mathrm{T}_{\max }$ values found for PHB and PLA composites.

\begin{tabular}{cccccc}
\hline PHB Systems & $\mathrm{T}_{\text {onset }}\left({ }^{\circ} \mathrm{C}\right)$ & $\mathrm{T}_{\max }\left({ }^{\circ} \mathrm{C}\right)$ & PLA Systems & $\mathrm{T}_{\text {onset }}\left({ }^{\circ} \mathrm{C}\right)$ & $\mathrm{T}_{\max }\left({ }^{\circ} \mathrm{C}\right)$ \\
\hline PHB & 256 & 270 & PLA & 320 & 347 \\
PHB/MCC3 & 266 & 279 & PLA/MCC3 & 332 & 354 \\
PHB/MCC5 & 224 & 238 & PLA/MCC5 & 322 & 342 \\
PHB/MCC7 & 251 & 267 & PLA/MCC7 & 317 & 342 \\
PHB/TMCC3 & 272 & 286 & PLA/TMCC3 & 330 & 350 \\
PHB/TMCC5 & 257 & 271 & PLA/TMCC5 & 338 & 359 \\
PHB/TMCC7 & 256 & 270 & PLA/TMCC7 & 319 & 341 \\
\hline
\end{tabular}

the addition of MCC at $5 \mathrm{wt} \%$ caused an important decrease on this thermal behavior. This result suggests that PHB/MMC5 system formed a non-homogeneous material due to the inefficient dispersion of the MMC into PHB matrix. On the other hand, the samples containing $3 \mathrm{wt} \%$ of both microcrystalline cellulose filler (MCC and TMCC) demonstrated an increase on the thermal stability. Compared to unfilled $\mathrm{PHB}, \mathrm{PHB} / \mathrm{MCC} 3$ had an increase of $10^{\circ} \mathrm{C}$ on Tonset and $9^{\circ} \mathrm{C}$ on Tmax, while PHB/TMCC3 had an increase of $14^{\circ} \mathrm{C}$ and $16^{\circ} \mathrm{C}$ on Tonset and Tmax, respectively. This result indicates that for PHB composites the best proportion of cellulose filler was $3 \mathrm{wt} \%$ and that the ultrasonication treatment of this filler was important, making the improvement of this property more effective.

For PLA biocomposites, the results (Table 2 and Figure 2) showed that the addition of 5 and $7 \mathrm{wt} \%$ of MMC did not cause significantly change on the thermal stability of the PLA matrix, while the addition of $3 \mathrm{wt} \%$ promoted an improvement on the thermal performance of the PLA matrix, with an increase of $12^{\circ} \mathrm{C}$ on Tonset and $7^{\circ} \mathrm{C}$ on Tmax. For the samples prepared with TMCC, the best system composition was with TMCC $5 \mathrm{wt} \%$, exhibiting an increase of $18^{\circ} \mathrm{C}$ on Tonset and $12^{\circ} \mathrm{C}$ on Tmax. Comparing the results obtained for the prepared systems with MCC and TMCC, it was clear that the treated microcrystalline cellulose (TMCC) promotes a better thermal performance for both biodegradable matrices studied in this work.

\subsubsection{Differential Scanning Calorimetry (DSC)}

The glass transition temperature $(\mathrm{Tg})$, the melting temperature $(\mathrm{Tm})$ and the crystallization temperature (Tc) obtained from DSC are denoted in Table 3.

According to results, the glass transition temperature ( $\mathrm{Tg}$ ), the melting temperature $(\mathrm{Tm})$ and the crystallization temperature (Tc) found for PHB were $3.6^{\circ} \mathrm{C}, 174^{\circ} \mathrm{C}$ and $48^{\circ} \mathrm{C}$, respectively and for PLA were $62^{\circ} \mathrm{C}, 174^{\circ} \mathrm{C}$ and $99^{\circ} \mathrm{C}$, respectively. Analyzing the results obtained for biocomposites prepared in this study with both biodegradable matrices and both cellulose filler types, it was possible to notice that the addition of MCC or TMCC did not affect these thermal properties in any of the proportions studied, maintaining practically unchanged these thermal characteristics Tg, Tm and Tc of the PHB and PLA matrices. 
Table 3. Thermal data obtained by DSC for PHB, PLA and their biocomposites.

\begin{tabular}{cccccccc}
\hline PHB systems & $\mathrm{Tg}\left({ }^{\circ} \mathrm{C}\right)$ & $\mathrm{Tm}\left({ }^{\circ} \mathrm{C}\right)$ & $\mathrm{Tc}\left({ }^{\circ} \mathrm{C}\right)$ & PLA systems & $\mathrm{Tg}\left({ }^{\circ} \mathrm{C}\right)$ & $\mathrm{Tm}\left({ }^{\circ} \mathrm{C}\right)$ & $\mathrm{Tc}\left({ }^{\circ} \mathrm{C}\right)$ \\
\hline PHB & 3.6 & 174 & 48 & PLA & 62 & 174 & 99 \\
PHB/MCC3 & 3.5 & 173 & 48 & PLA/MCC3 & 62 & 174 & 100 \\
PHB/MCC5 & 3.7 & 174 & 49 & PLA/MCC5 & 62 & 174 & 99 \\
PHB/MCC7 & N.D.* & 173 & 45 & PLA/MCC7 & 62 & 174 & 97 \\
PHB/TMCC3 & 3.4 & 173 & 46 & PLA/TMCC3 & 62 & 174 & 98 \\
PHB/TMCC5 & 3.5 & 173 & 45 & PLA/TMCC5 & 62 & 174 & 97 \\
PHB/TMCC7 & N.D. $*$ & 173 & 43 & PLA/TMCC7 & 62 & 174 & 98 \\
\hline
\end{tabular}

\subsubsection{X-Ray Diffraction (XRD)}

Figure 3 and Figure 4 present the diffractograms obtained for PHB and PLA biocomposites, respectively, as well as for isolated MCC, TMCC, PHB and PLA. For MCC and TMCC it was found characteristics peaks related to cellulose at $2 \theta$ around $14.5^{\circ}, 16.5^{\circ}, 22.5^{\circ}$ and $35^{\circ}$ attributed to the planes of (110), (1 - 10), (200) and (004), respectively [45] [46].

$\mathrm{PHB}, \mathrm{PHB} / \mathrm{MCC}$ and $\mathrm{PHB} / \mathrm{TMCC}$ systems revealed a similar crystalline profile corresponding to orthorhombic crystal planes (Figure 3 ). It was observed two strong scattering intensity peaks detected around $2 \theta 13^{\circ}$ and $17^{\circ}$, which is assigned to the (020) and (110) planes of the orthorhombic unit cell, respectively. Other weaker reflections located at around $22.5^{\circ}, 26^{\circ}, 27^{\circ}$ and $31^{\circ}$ correspond to (111), (121), (040) and (002), respectively. Furthermore, all the samples presented a small amount of orthorhombic $\beta$-form crystal with zig-zag conformation, as revealed by the reflection of the (021) plane located at around $2 \theta=20^{\circ}$ [47] [48] [49]. Compared to pure PHB, some PHB/MMC and PHB/TMCC systems presented slight changes in peak intensities, which can be attributed to changes in the crystalline profile. The calculated degree of crystallinity for studied materials is denoted in Table 4. It was found that for PHB/MCC systems, the formulation containing 5 and $7 \mathrm{wt} \%$ of MCC presented an increase of $5.8 \%$ and $6.6 \%$ on degree of crystallinity, respectively, while PHB/MCC3 did not present significant changes. On the other hand, PHB/TMCC formulations showed opposite behavior, such that the formulations containing 5 and $7 \mathrm{wt} \%$ of TMCC maintained the degree of crystallinity practically unchanged and the PHB/TMCC3 formulation presented an increase of $7.3 \%$ on this parameter. This result suggests that MCC and TMCC influence differently on the PHB matrix. The increase in the peak intensity located at $2 \theta=22.5^{\circ}$ observed for systems containing 5 and $7 \mathrm{wt} \%$ of MCC and TMCC is attributed to (002) plane of the cellulose fillers, which are present in higher proportions for these compositions.

XRD patterns obtained for PLA, PLA/MCC and PLA/TMCC are presented in Figure 4. It was possible to observe that PLA presented a typical semi-crystalline diffractogram with a very strong reflection at $2 \theta=16.9^{\circ}$ due to diffraction from (110) and/or (200) planes, besides the less intense peaks at $19.3^{\circ}$ attributed to the reflection of the (203) plane [50] [51]. Similar diffraction patterns were observed 

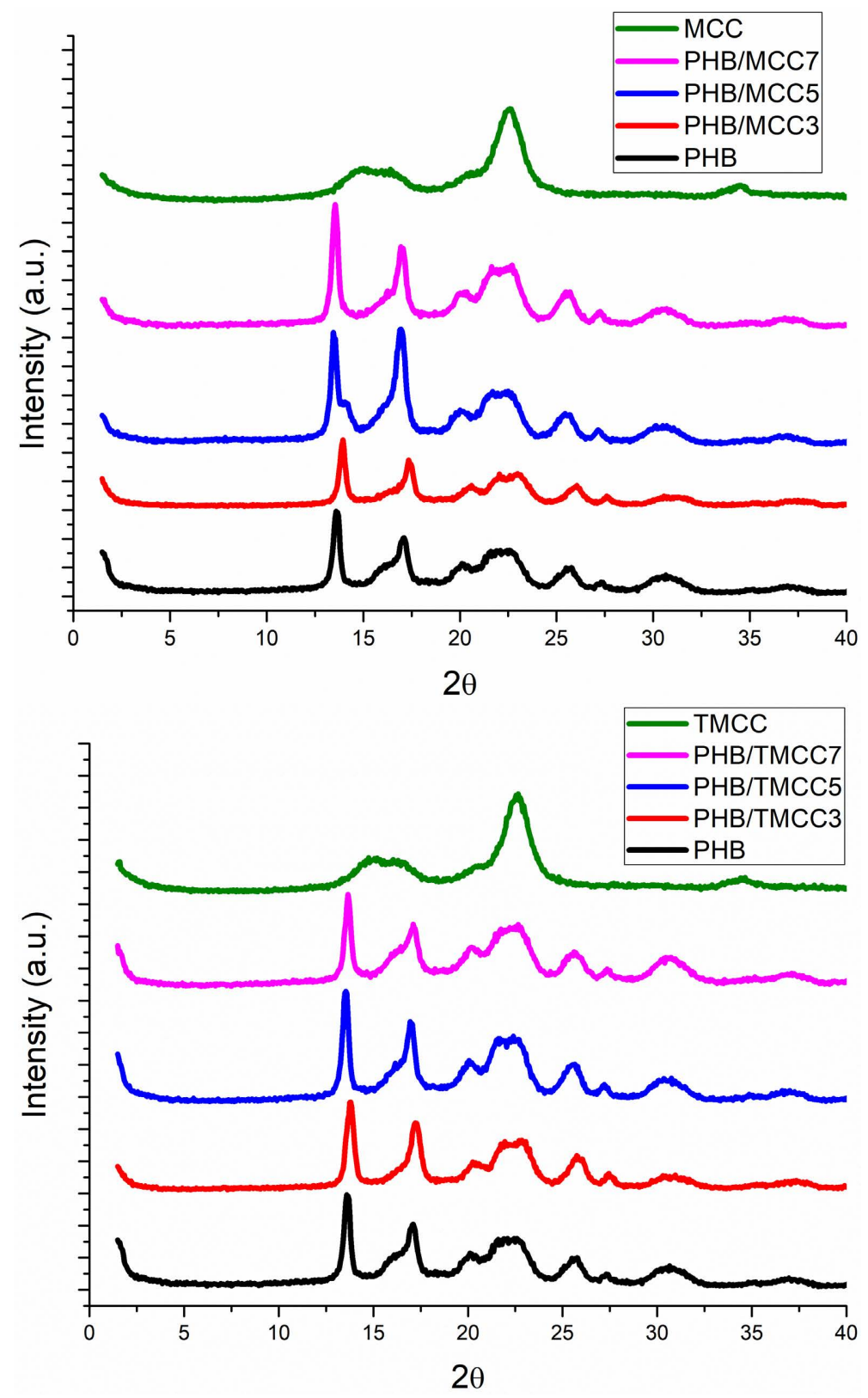

Figure 3. Diffractograms obtained for PHB, PHB/MCC and PHB/TMCC systems.

Table 4. Degree of crystallinity of PHB, PLA and their biocomposites.

\begin{tabular}{cccc}
\hline PHB systems & Xc (\%) & PLA systems & Xc (\%) \\
\hline PHB & 67 & PLA & 46 \\
PHB/MCC3 & 69 & PLA/MCC3 & 50 \\
PHB/MCC5 & 73 & PLA/MCC5 & 42 \\
PHB/MCC7 & 74 & PLA/MCC7 & 41 \\
PHB/TMCC3 & 75 & PLA/TMCC3 & 48 \\
PHB/TMCC5 & 68 & PLA/TMCC5 & 44 \\
PHB/TMCC7 & 68 & PLA/TMCC7 & 39
\end{tabular}



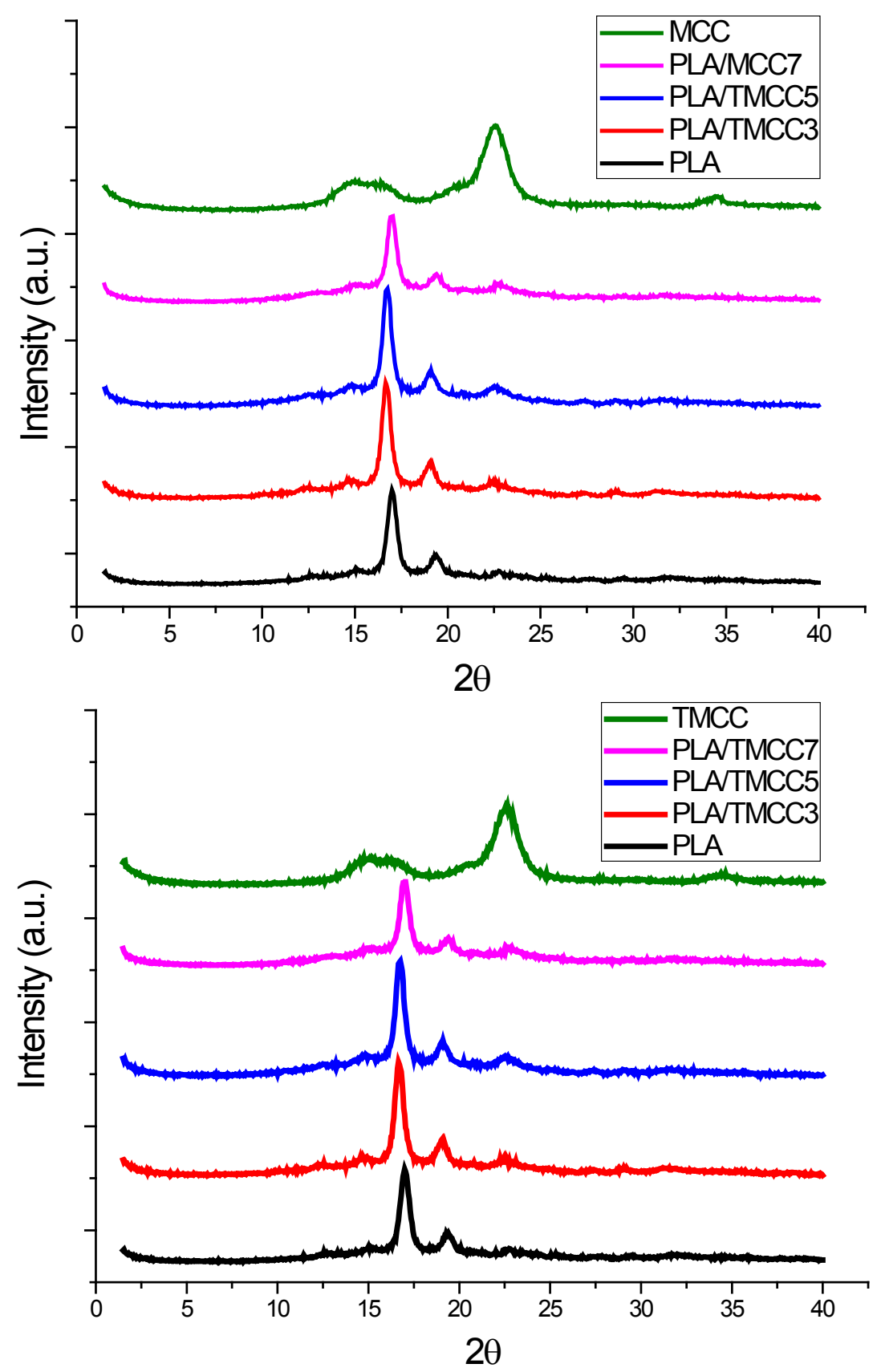

Figure 4. Diffractograms obtained for PLA, PLA/MCC and PLA/TMCC systems.

in PLA/MCC and PLA/TMCC systems, which indicates that the incorporation of these cellulose fillers did not affect the crystal forms of PLA. Moreover, it was possible verify the peak at around $2 \theta=22.5^{\circ}$, which is attributed to (002) plane of cellulose fillers. Regarding the degree of crystallinity, it was seen that the sample containing $3 \mathrm{wt} \%$ for both cellulose fillers (MCC and TMCC) presented a slight increase on this parameter. PLA/MCC3 PLA/TMCC3 presented an increase of $4.2 \%$ and $2.0 \%$ on the degree of crystallinity, respectively. The other formulations presented a slight decrease, especially PLA/TMCC7 which revealed a $7.1 \%$ decrease on this parameter (Table 4 ). 


\subsubsection{Time Domain-Nuclear Magnetic Ressonance (TD-NMR)}

TD-NMR is an unconventional technique that provides information about molecular dynamic behavior and homogeneity of materials at the molecular level. On this account, TD-NMR is crucial for the characterization of hybrid materials, such as polymer composites and nanocomposites [42] [43] [44] [52].

The molecular dynamic of the materials was evaluated through hydrogen spin-lattice relaxation time $(\mathrm{T} 1 \mathrm{H})$ and their homogeneity were investigated by fitting domain distribution curves. These plots provide information on homogeneity, according to the number of curves present in the plot and these curves' base width.

Regarding relaxation measurements, it was observed, in general, a tendency of progressive decrease in the $\mathrm{T}_{1} \mathrm{H}$ values with the increase in microcrystalline cellulose proportion, regardless of the type (Table 5). This behavior was observed for both PHB and PLA matrices, which indicates that both MCC and TMCC promoted an increase on the molecular freedom of polymer chains. This points to a good dispersion of these fillers, which presumably led to a reduction of the inter- and intramolecular interaction within the polymer chains. Comparing the systems prepared with MCC and TMCC at the same filler proportions, for PHB biocomposites it was observed that all systems prepared with TMCC had lower $\mathrm{T}_{1} \mathrm{H}$ values, indicating a more important change on the PHB matrix. This result was clearly observed for PHB systems containing $5 \mathrm{wt} \%$ of cellulose filler, where PHB/TMCC5 presented a more pronounced decrease of $\mathrm{T}_{1} \mathrm{H}$ value $(565 \mathrm{~ms})$ compared to PHB/MCC5 $(582 \mathrm{~ms}$ ), which suggests a better dispersion when TMCC is used in this proportion.

PLA biocomposites presented a different behavior, showing higher $\mathrm{T}_{1} \mathrm{H}$ values for the biocomposites prepared with TMCC at 3 and $7 \mathrm{wt} \%$ and lower $\mathrm{T}_{1} \mathrm{H}$ value for PLA/TMCC5. This result indicated that for systems containing 3 and $7 \mathrm{wt} \%$ of cellulose filler, the MCC was more effective on the dispersion and for system containing $5 \mathrm{wt} \%$ of filler, the TMCC presented greater influence, as seen by the lowest $\mathrm{T}_{1} \mathrm{H}$ values found, when compared to systems containing the same proportion of cellulose, which indicates a better cellulose filler dispersion. The results obtained for $\mathrm{T} 1 \mathrm{H}$ values indicate that MCC and TMCC act differently on the filler dispersion when added in the PHB or PLA matrices. Regarding to homogeneity at

Table 5. $\mathrm{T}_{1} \mathrm{H}$ values obtained for PHB, PLA and their biocomposites.

\begin{tabular}{cccc}
\hline PHB systems & T1H $(\mathrm{ms}) \pm 2 \%$ & PLA systems & T1H (ms) $\pm 2 \%$ \\
\hline PHB & 643 & PLA & 724 \\
PHB/MCC3 & 580 & PLA/MCC3 & 679 \\
PHB/MCC5 & 582 & PLA/MCC5 & 708 \\
PHB/MCC7 & 533 & PLA/MCC7 & 625 \\
PHB/TMCC3 & 577 & PLA/TMCC3 & 697 \\
PHB/TMCC5 & 565 & PLA/TMCC5 & 678 \\
PHB/TMCC7 & 529 & PLA/TMCC7 & 640 \\
\hline
\end{tabular}


molecular level it was observed through domain distribution curves (Figure 5 and Figure 6) that for PHB and PLA biocomposites systems, the most homogeneous
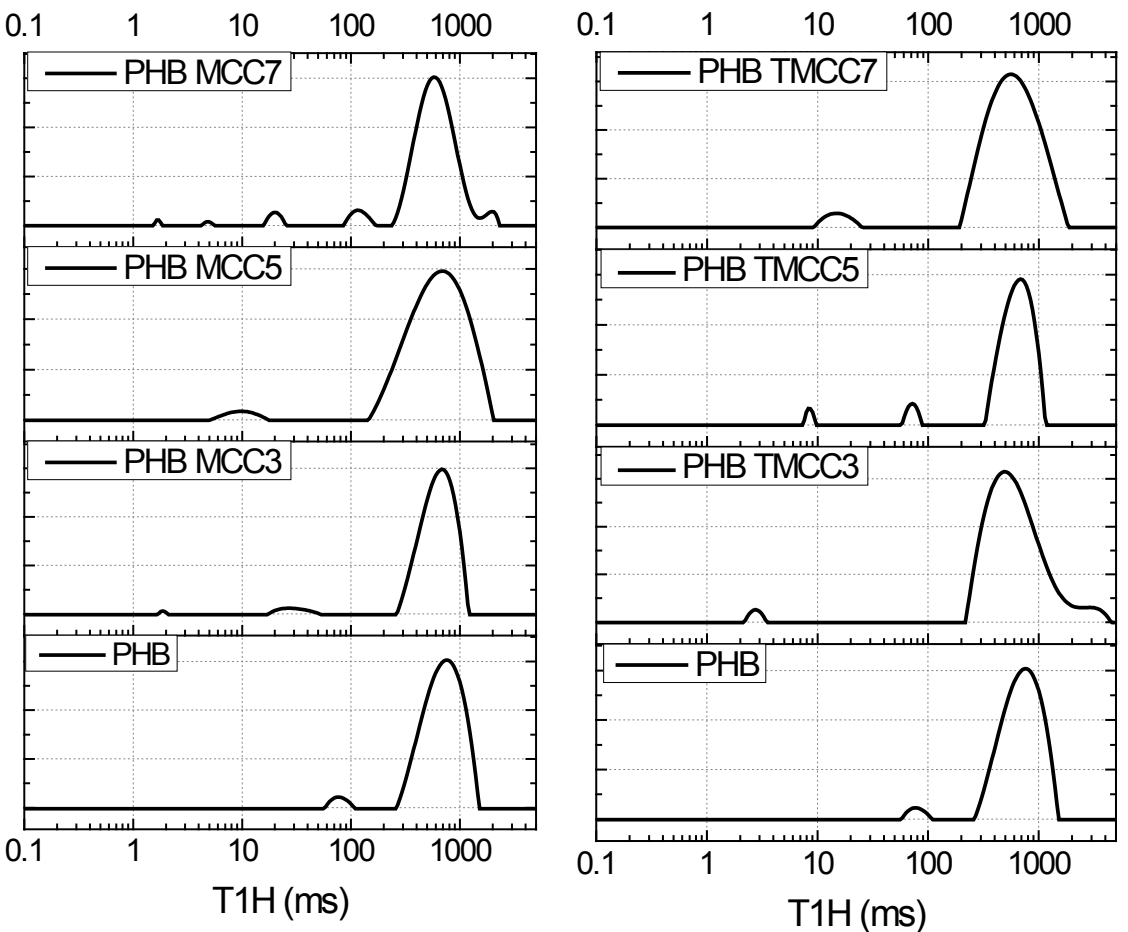

Figure 5. Domain distribution curves obtained for PHB/MCC and PHB/TMCC biocomposites.
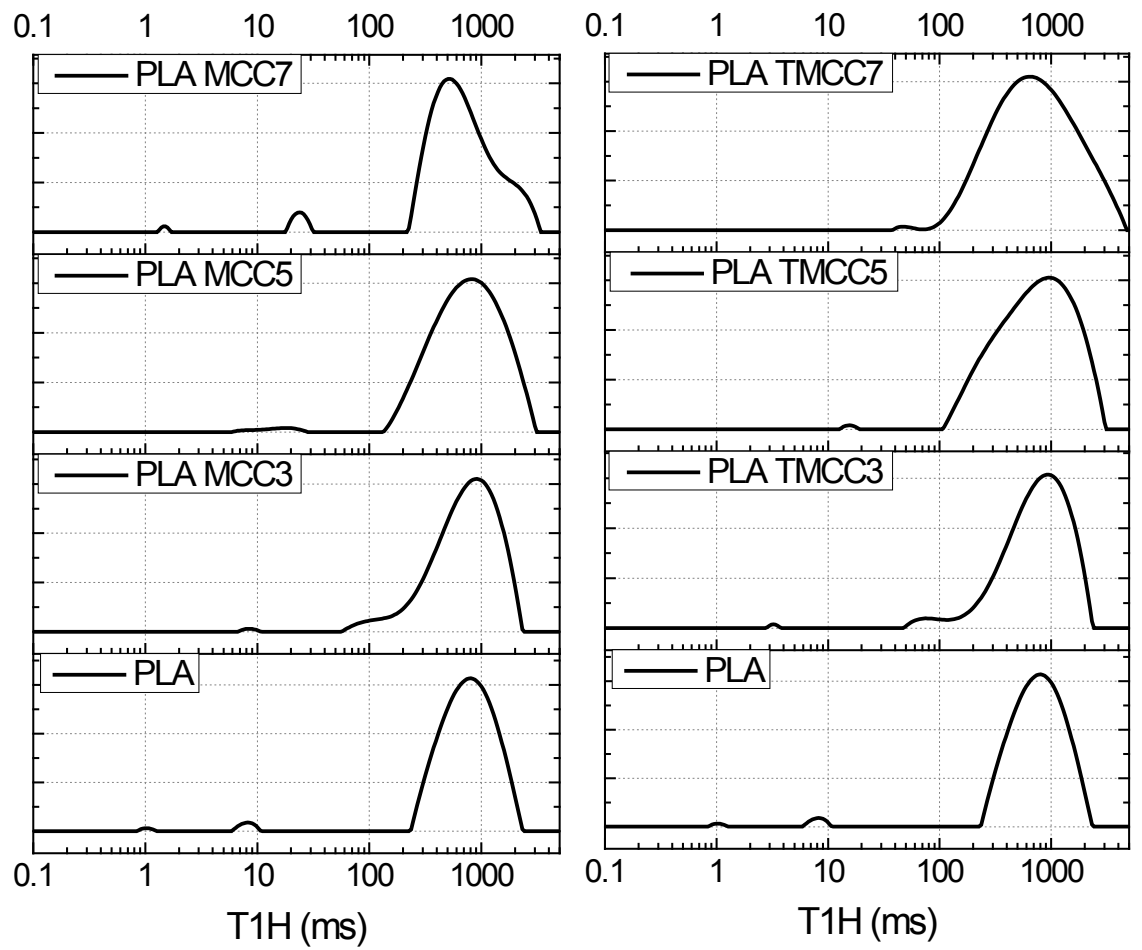

Figure 6. Domain distribution curves obtained for PLA/MCC and PLA/TMCC biocomposites. 
systems were the formulations containing $3 \mathrm{wt} \%$ for both MCC and TMCC. This result justifies the increase on the thermal stability observed from TGA for these systems.

\section{Conclusion}

Treated and untreated microcrystalline cellulose were separately incorporated into the PHB and PLA matrices in order to develop fully biodegradable composites. Important properties of the prepared biocomposites were evaluated, considering the effect of type and proportion of microcrystalline cellulose incorporated. The main results showed that MCC and TMCC influenced differently in PHB and PLA matrices. It was found that TMCC filler promoted better thermal stability for both studied matrices and that MCC and TMCC caused slight but discontinuous changes in the degree of crystallinity of the studied systems. TDNMR technique provided consistent information about the homogeneity achieved in the prepared systems, indicating that lower proportions of cellulose fillers result in more homogeneous systems, which justifies the better thermal stability for both $3 \mathrm{wt} \%$ compositions. The results found in this work suggest that PLA and PHB biocomposites containing microcrystalline cellulose as dispersed phase are promising alternatives to replace non-biodegradable synthetic polymers. Further analyses to evaluate mechanical and barrier properties, as well as swelling tests are some prospects to point out the potential applications of these materials.

\section{Acknowledgements}

The authors gratefully acknowledge the financial support provided by FAPERJ.

\section{Conflicts of Interest}

The authors declare no conflicts of interest regarding the publication of this paper.

\section{References}

[1] Lambert, S. and Wagner, M. (2017) Environmental Performance of Bio-Based and Biodegradable Plastics: The Road Ahead. Chemical Society Reviews, 46, 6855-6871. https://doi.org/10.1039/C7CS00149E

[2] Nagalakshmaiah, M., Afrin, S., Malladi, R.P., Elkoun, S., Robert, M., Ansari, M.A., Svedberg, A. and Karim, Z. (2019) Biocomposites: Present Trends and Challenges for the Future. In: Green Composites for Automotive Applications, Elsevier Science, Cambridge, 197-215. https://doi.org/10.1016/B978-0-08-102177-4.00009-4

[3] Panda, A.K., Singh, R.K. and Mishra, D.K. (2010) Thermolysis of Waste Plastics to Liquid Fuel: A Suitable Method for Plastic Waste Management and Manufacture of Value Added Products-A World Prospective. Renewable and Sustainable Energy Reviews, 14, 233-248. https://doi.org/10.1016/j.rser.2009.07.005

[4] Hidayah, N. and Syafrudin (2018) A Review on Landfill Management in the Utilization of Plastic Waste as an Alternative Fuel. E3S Web of Conferences, 31, 05013. https://doi.org/10.1051/e3sconf/20183105013

[5] Shaghaleh, H., Xu, X. and Wang, S. (2018) Current Progress in Production of Bio- 
polymeric Materials Based on Cellulose, Cellulose Nanofibers, and Cellulose Derivatives. RSC Advances. 8, 825-842. https://doi.org/10.1039/C7RA11157F

[6] Mohanty, A.K., Misra, M. and Hinrichsen, G. (2000) Biofibres, Biodegradable Polymers and Biocomposites: An Overview. Macromolecular Materials Engineering, 276, 1-24. https://doi.org/10.1002/(SICI)1439-2054(20000301)276:1<1::AID-MAME1>3.0.CO; $\underline{2-\mathrm{W}}$

[7] Mohanty, A.K., Misra, M. and Drzal, L.T. (2002) Sustainable Bio-Composites from Renewable Resources Opportunities and Challenges in the Green Material World. Journal of Polymers the Environment, 10, 19-26. https://doi.org/10.1023/A:1021013921916

[8] Mecking, S. (2004) Nature or Petrochemistry Biologically Degradable Materials. Angewandte Chemie International Edition, 43, 1078-1085.

https://doi.org/10.1002/anie.200301655

[9] Davis, G. and Song, J.H. (2006) Biodegradable Packaging Based on Raw Materials from Crops and Their Impact on Waste Management. Industrial Crops and Products, 23, 147. https://doi.org/10.1016/j.indcrop.2005.05.004

[10] Harada, J., Amorim, C.A., Braga, P.L., Machado, L.D.B., Oliveira, R.R., Cabral, N., Abner, M., Jose, R.N., Silva, L.G.A. and Rosa, D.S. (2017) Characterization of Biodegradable Mulch Black Films Incorporated with Organics Fertilizers and Rice Husk Ash. Proceedings of the 146th TMS Annual Meeting and Exhibition, San Diego, 26 February-2 March 2017.

[11] Thomas, S.K., Parameswaranpillai, J., Krishnasamy, S., Begum, P.M.S., Nandi, D., Siengchin, S., George, J.J., Hameed, N., Salim, N.V. and Sienkiewicz, N. (2021) A Comprehensive Review on Cellulose, Chitin, and Starch as Fillers in Natural Rubber Biocomposites. Carbohydrate Polymer Technologies and Applications, 2, Article ID: 100095. https://doi.org/10.1016/j.carpta.2021.100095

[12] Azeredo, H.M.C. (2009) Nanocomposites for Food Packaging Applications. Food Research International, 42, 1240-1253. https://doi.org/10.1016/j.foodres.2009.03.019

[13] Bledzki, A.K. and Gassan, J. (1999) Composites Reinforced with Cellulose Based Fibres. Progress in Polymer Science, 24, 221-274.

https://doi.org/10.1016/S0079-6700(98)00018-5

[14] Nakagaito, A.N., Iwamoto, S. and Yano, H. (2005) Bacterial Cellulose: The Ultimate Nano-Scalar Cellulose Morphology for the Production of High Strength Composites. Applied Physics A: Materials Science \& Processing, 80, 93-97. https://doi.org/10.1007/s00339-004-2932-3

[15] Taylor, N.G. (2008) Cellulose Biosynthesis and Deposition in Higher Plants. New Phytologist, 178, 239-252. https://doi.org/10.1111/j.1469-8137.2008.02385.x

[16] Samir, M.A.S.A., Alloin, F. and Dufresne, A. (2005) Review of Recent Research into Cellulosic Whiskers, Their Properties and Their Application in Nanocomposite Field. Biomacromolecules, 6, 612-626. https://doi.org/10.1021/bm0493685

[17] Lin, N., Chen, G., Huang, J., Dufresne, A. and Chang, P.R. (2009) Structure and Mechanical Properties of Poly (Lactic Acid): A Case of Cellulose Whisker-GraftPolycaprolactone. Journal of Applied Polymer Science, 113, 3417-3425. https://doi.org/10.1002/app.30308

[18] Bras, J., Hassan, M.L., Bruzesse, C., Hassan, E.A., Nahla, A., El-Wakil, N.A. and Dufresne, A. (2010) Mechanical, Barrier, and Biodegradability Properties of Bagasse Cellulose Whiskers Reinforced Natural Rubber Nanocomposites. Industrial Crops and Products, 32, 627-633. https://doi.org/10.1016/j.indcrop.2010.07.018 
[19] Ten, E., Turtle, J., Bahr, D., Jiang, L. and Wolcott, M. (2010) Thermal and Mechanical Properties of Poly(3-Hydroxybutyrate-Co-3-Hydroxyvalerate)/Cellulose Nanowhiskers Composites. Polymer, 51, 2652-2660.

https://doi.org/10.1016/j.polymer.2010.04.007

[20] Yu, H.-Y., Qin, Z.-Y., Liu, L., Yang, X.-G., Zhou, Y. and Yao, J.-M. (2013) Comparison of the Reinforcing Effects for Cellulose Nanocrystals Obtained by Sulfuric and Hydrochloric Acid Hydrolysis on the Mechanical and Thermal Properties of Bacterial Polyester. Composites Science and Technology, 87, 22-28.

https://doi.org/10.1016/j.compscitech.2013.07.024

[21] Cacciotti, I., Fortunati, E., Puglia, D., Kenny, J.M. and Nanni, F. (2014) Effect of Silver Nanoparticles and Cellulose Nanocrystals on Electrospun Poly (Lactic) Acid Mats: Morphology, Thermal Properties and Mechanical Behavior. Carbohydrate Polymers, 103, 22-31. https://doi.org/10.1016/j.carbpol.2013.11.052

[22] Babaee, M., Jonoobi, M., Hamzeh, Y. and Ashori, A. (2015) Biodegradability and Mechanical Properties of Reinforced Starch Nanocomposites Using Cellulose Nanofibers. Carbohydrate Polymers, 132, 1-8. https://doi.org/10.1016/j.carbpol.2015.06.043

[23] Santos, F.A. and Tavares, M.I.B. (2015) Development of Biopolymer/Cellulose/ Silica Nanostructured Hybrid Materials and Their Characterization by NMR Relaxometry. Polymer Testing, 47, 92-100. https://doi.org/10.1016/j.polymertesting.2015.08.008

[24] Rahman, M.M., Afrin, S. and Haque, P. (2014) Characterization of Crystalline Cellulose of Jute Reinforced Poly (Vinyl Alcohol) (PVA) Biocomposite Film for Potential Biomedical Applications. Progress in Biomaterials, 3, 23-31.

https://doi.org/10.1007/s40204-014-0023-x

[25] Kakroodi, A.R., Cheng, S., Sain, M. and Asiri, A. (2014) Mechanical, Thermal, and Morphological Properties of Nanocomposites Based on Polyvinyl Alcohol and Cellulose Nanofiber from Aloe Vera Rind. Journal of Nanomaterials, 2014, 1687-4110. https://doi.org/10.1155/2014/903498

[26] Pracella, M., Haque, M.-U. and Puglia, D. (2014) Morphology and Properties Tuning of PLA/Cellulose Nanocrystals Bio-Nanocomposites by Means of Reactive Functionalization and Blending with PVAc. Polymer, 16, 3720-3728. https://doi.org/10.1016/j.polymer.2014.06.071

[27] Zhang, C., Dan, Y., Peng, J., Turng, L.-S., Sabo, R. and Clemons, C. (2014) Thermal and Mechanical Properties of Natural Rubber Composites Reinforced with Cellulose Nanocrystals from Southern Pine. Advances in Polymer Technology, 33, S1. https://doi.org/10.1002/adv.21448

[28] Zulkifli, N.I., Samat, N., Anuar, H. and Zainuddin, N. (2015) Mechanical Properties and Failure Modes of Recycled Polypropylene/Microcrystalline Cellulose Composites. Material \& Design, 69, 114-123. https://doi.org/10.1016/j.matdes.2014.12.053

[29] Sonseca, A., Sahuquillo, O., Foster, E.J. and Giménez, E. (2015) Mechanical Properties and Degradation Studies of Poly (Mannitol Sebacate)/Cellulose Nanocrystals Nanocomposites. RSC Advances, 5, 55879-55891. https://doi.org/10.1039/C5RA06768E

[30] Mahfoudhi, N. and Boufi, S. (2017) Nanocellulose: A Challenging Nanomaterial towards Environment Remediation. In: Cellulose-Reinforced Nanofibre Composites, Elsevier, Amsterdam, 277-304.

https://doi.org/10.1016/B978-0-08-100957-4.00012-7 
[31] Toha, N., Yaa'cob, W.M.H.W., Razali, N.A.M., Rusdi, R.A.A., Ismail, A., Ahmad, K.Z.K. and Abdul, F. (2018) Preliminary Development of Laminated Nanocomposite from Nanocellulose-Kevlar for Military Application. International Journal of Current Science, Engineering \& Technology, 1, 566-570. https://doi.org/10.30967/ijcrset.1.S1.2018.566-570

[32] Yasim-Anuar, T.A.T., Ariffin, H., Norrrahim, M.N.F, Hassan, M.A, Andou, Y., Tsukegi, T. and Nishida, H. (2020) Well-Dispersed Cellulose Nanofiber in Low Density Polyethylene Nanocomposite by Liquid-Assisted Extrusion. Polymers, 12, 927-943. https://doi.org/10.3390/polym12040927

[33] Norrrahim, M.N.F., Yasim-Anuar, T.A.T., Jenol, M.A., Mohd Nurazzi, N., Ilyas, R.A. and Sapuan, S. (2021) Performance Evaluation of Cellulose Nanofiber Reinforced Polypropylene Biocomposites for Automotive Applications. In: Biocomposite and Synthetic Composites for Automotive Applications, Elsevier, Amsterdam, 119-215. https://doi.org/10.1016/B978-0-12-820559-4.00007-9

[34] Agoda-Tandjawa, G., Durand, S., Berot, S., Blassel, C., Gaillard, C., Garnier, C. and Doublier, J.L. (2010) Rheological Characterization of Microfibrillated Cellulose Suspensions after Freezing. Carbohydrate Polymers, 80, 677-686. https://doi.org/10.1016/j.carbpol.2009.11.045

[35] Cao, Y., Zavattieri, P., Youngblood, J., Moon, R. and Weiss, J. (2016) The Relationship between Cellulose Nanocrystal Dispersion and Strength. Construction and Building Materials, 119, 71-79. https://doi.org/10.1016/j.conbuildmat.2016.03.077

[36] Parveen, S., Rana, S., Ferreira, S., Filho, A. and Fangueiro, R. (2018) Ultrasonic Dispersion of Micro Crystalline Cellulose for Developing Cementitious Composites with Excellent Strength and Stiffness. Industrial Crops and Products, 122, 156-165. https://doi.org/10.1016/j.indcrop.2018.05.060

[37] Beuguel, Q., Tavares, J.R., Carreau, P.J. and Heuzey, M.C. (2018) Ultrasonication of Spray- and Freeze-Dried Cellulose Nanocrystals in Water. Journal of Colloid and Interface Science, 516, 23-33. https://doi.org/10.1016/j.jcis.2018.01.035

[38] Sayyed, A.J., Mohite, L.V., Deshmukh, N.A. and Pinjari, D.V. (2018) Effect of Ultrasound Treatment on Swelling Behavior of Cellulose in Aqueous N-Methylmorpholine-N-Oxide Solution. Ultrasonics Sonochemistry, 49, 161-168. https://doi.org/10.1016/j.ultsonch.2018.07.042

[39] Shojaeiarani, J., Bajwa, D. and Holt, G. (2020) Sonication Amplitude and Processing Time Influence the Cellulose Nanocrystals Morphology and Dispersion. Nanocomposites, 6, 41-46. https://doi.org/10.1080/20550324.2019.1710974

[40] Girard, M., Vidal, D., Bertrand, F., Tavares, J.R. and Heuzey, M.C. (2021) Evidence-Based Guidelines for the Ultrasonic Dispersion of Cellulose Nanocrystals. UItrasonics Sonochemistry, 71, Article ID: 105378. https://doi.org/10.1016/j.ultsonch.2020.105378

[41] Santos, F.A., Iulianelli, G.C.V. and Tavares, M.I.B. (2017) Effect of Microcrystalline and Nanocrystals Cellulose Fillers in Materials Based on PLA Matrix. Polymer Testing, 61, 280-288. https://doi.org/10.1016/j.polymertesting.2017.05.028

[42] Tavares, M.I.B., Dutra, J.C., Nascimento, T., Iulianelli, G.C.V. and Merat, P.P. (2020) Effect of Molybdenum Trioxide in the Behavior of Poly(vinylalcohol) Nanocomposites Systems Focusing New Systems for Protection against COVID-19. Journal of Research Updates in Polymer Science, 9, 89-95.

https://doi.org/10.4236/msa.2015.610088

[43] Iulianelli, G.C.V., Sebastião, P.J.O., Tavares, M.I.B. and Santos, F.A. (2015) Influence of Organoclay Structure on Nanostructured Materials Based on EVA. Mate- 
rials Sciences and Applications, 6, 860-868. https://doi.org/10.1016/j.polymertesting.2017.11.018

[44] Iulianelli, G.C.V., David, G.S., Santos, T.N., Sebastião, P.J.O. and Tavares, M.I.B. (2018) Influence of $\mathrm{TiO}_{2}$ Nanoparticle on the Thermal, Morphological and Molecular Characteristics of PHB Matrix. Polymer Testing, 65, 156-162. https://doi.org/10.1016/j.indcrop.2018.08.051

[45] Kouadri, I. and Satha, H. (2018) Extraction and Characterization of Cellulose and Cellulose Nanofibers from Citrullus colocynthis Seeds. Industrial Crops and Products, 124, 787-796.

[46] Gong, J., Li, J., Xu, J., Xiang, Z. and Mo, L. (2017) Research on Cellulose Nanocrystals Produced from Cellulose Sources with Various Polymorphs. RSC Advances, 7, 33486-33493. https://doi.org/10.1039/C7RA06222B

[47] Frone, A.N., Nicolae, C.A., Eremia, M.C., Ghiurea, V.T.M., Chiulan, I., Radu, E., Damian, C.M. and Panaitescu, D.M. (2020) Low Molecular Weight and Polymeric Modifiers as Toughening Agents in Poly(3-Hydroxybutyrate) Films. Polymers, 12, 2446. https://doi.org/10.3390/polym12112446

[48] Petrovova, E., Giretova, M., Kvasilova, A., Benada, O., Danko, J., Medvecky, L. and Sedmera, D. (2019) Preclinical Alternative Model for Analysis of Porous Scaffold Biocompatibility Applicable in Bone Tissue Engineering. ALTEX-Alternatives to Animal Experimentation, 36, 121-130. https://doi.org/10.14573/altex.1807241

[49] Mottin, A.C., Ayres, E., Oréfice, R.L. and Câmara, J.J.D. (2016) What Changes in Poly(3-Hydroxybutyrate) (PHB) When Processed as Electrospun Nanofibers or Thermo-Compression Molded Film? Materials Research, 19, 57-66. https://doi.org/10.1590/1980-5373-MR-2015-0280

[50] Farid, T., Herrera, V.N. and Kristiina, O. (2018) Investigation of Crystalline Structure of Plasticized Poly(lactic acid)/Banana Nanofibers Composites. IOP Conferences Series. Materials Science and Engineering, 369, Article ID: 012031. https://doi.org/10.1088/1757-899X/369/1/012031

[51] Gong, M., Zhao, Q., Dai, L., Li, Y. and Jiang, T. (2017) Fabrication of Polylactic Acid/Hydroxyapatite/Graphene Oxide Composite and Their Thermal Stability, Hydrophobic and Mechanical Properties. Journal of Asian Ceramic Societies, 5, 160-168. https://doi.org/10.1016/j.jascer.2017.04.001

[52] Santos, F.A., Iulianelli, G.C.V. and Tavares, M.I.B. (2017) Development and Properties Evaluation of Bio-Based PLA/PLGA Blend Films Reinforced with Microcrystalline Cellulose and Organophilic Silica. Polymer Engineering \& Science, 57, 464-472. https://doi.org/10.1002/pen.24447 